\title{
Construction of the Education Quality of General Primary School and Teacher Training Model in Chongqing
}

\author{
Jiapeng Dai ${ }^{1}$ \\ ${ }^{1}$ Chongqing University of Education, Chongqing, 400067, China
}

Keywords: Chongqing City, Primary teacher, Teacher training

\begin{abstract}
Chongqing must attach great importance to the construction of teacher talents' quality in the process to achieve "Western Education Heights" and the problem of primary teachers training is increasingly attracted widespread attention. This paper thorough thinking the training model of Chongqing primary teachers and put forward reform measures for them.
\end{abstract}

\section{Introduction}

Self-contained classrooms in primary teaching is the trend of our primary school education becoming more globalization and general teachers is the precondition, meanwhile, the problem of training quality of general teachers is catching more attentions. The key to the reform of primary education is the constriction of teachers and Chongqing as "Western Education Heights" must pay attention to the training of general teachers. Chongqing, as the "big municipality", existing significant differences between urban and rural, eastern region and western region, the main city and non-main city, and fully considering of those differences, the pre-employment training of primary teachers' quality cannot “one size fits all”.

\section{Analysis of the quality and ability general teachers should have}

Quality and ability is constitute by "knowledge, skill” and other "should know, should be" section, and values, self-positioning, the driving force, personality traits and other emotional intelligence sections, and have many properties like abstract, stability, hierarchy and relativity. According to the "Primary School Teacher Professional Standards (Trail)” promulgated by the Ministry of Education, combining the requirements of self-contained classrooms, general teacher should have the following characteristics except the quality and ability of teachers.

Compound knowledge. Pupils have a holistic, life-oriented understanding of the world and various natural phenomena which come from life contains differ disciplines knowledge, thus, they need a scientific and rational explanation from teachers. "According to Husserl and Habermas, the living world is a non-subject issue, foundational, intuitive and an integrated world of human life”, students need a multi-disciplinary knowledge teachers who bring them more knowledge enjoyment.

Primary general teachers will undertake all disciplines in primary school, which requires a solid compound knowledge to fulfill the teaching tasks in humanities, natural sciences and art and physical disciplines without partial subjects' phenomenon. The compound knowledge not only means a comprehensive subject knowledge, but also the education academic knowledge, which includes pedagogy, psychology and pedagogical content knowledge, so the compound knowledge is necessary.

Comprehensive quality. To achieve the goal of self-contained classrooms, bearing multiple 
tasks, and capable for class management, activities undertaken, etc. communication and coordination a number of management works, general teachers are required a strong comprehensive quality to meet the needs of practical work.

The comprehensive quality of primary general teachers mainly refers to necessary teaching skills, events management ability, exploration of school curriculum and other capabilities to adapt the teaching practice and capable of carrying out the appropriate campus activities matches pupils characteristics, and be able to apply school-based curriculum research and development based on the reality of primary education, forming an unique primary education development concept.

Feelings of rooted in primary education. The feelings of rooted in primary education refers to the general teacher should have the ideals to devote into primary education whole-heartedly. Emotion is the foundation to engage in their work and the driving forces for their performances.

The feeling of primary general teachers are mainly present as following aspects, loving each pupil, treating them as growing seedlings and giving more care to help them understand the world. Regarding the primary education as their lofty ideals, making it full of vitality through their own efforts, adapting to the request of new century; continuing to perceive the joy of achievement in their teaching activities and finding new growth point for themselves in the work.

\section{Analysis the training cycle model of general teachers}

“3+2" higher normal college training model in economic underdeveloped areas. The underdeveloped areas in Chongqing like the rural areas in southeast have few school-aged students with uneven ages which require to construct more rural primary schools and recruit more teachers to unfold the self-contained classrooms to meet the needs of school-aged children. The primary general teachers training in those regions can choose the " $3+2$ " higher normal college training model. It means choose a normal school with better conditions as the training base, orientation to recruit normal college students who finished the primary general teachers required basic qualities like the basic skills includes write, draw, speak, sing and play to master the skills of lecture and lesson plan presentation. After finished the learning in normal college stages, through academic qualification exam, they can accept junior college education and transferred to the local normal universities such as Chongqing Normal University, Yangtze Normal University and Chongqing University of Education. The advantages of this training model is short training cycle and capable training a large number of teachers which can effectively solve the problem of teachers shortage in rural areas and meet the needs of local primary education.

Using the bachelor model or the bachelor-master model in the main city of Chongqing or other economic developed areas. In the economic developed main city and other central cities like Wanzhou, Fuling, Yongzhou and Hechuan, they can launch the bachelor model or bachelor-master model to training primary education teachers for the relatively saturation teachers and a higher requirements. The bachelor model can choosing " $2+1+1$ " program, it means in the freshman and the sophomore stage, students are send to the 985, 211 comprehensive universities like Sichuan University, Chongqing University etc. to strengthening the comprehensive knowledge and abilities to meet the requirements of general teacher. The junior stage, they mainly study the teachers' skills and physical skills in normal college and in the senior stage, they will enter the local teacher training school, participant in the practice of primary education and teaching introspection to realize the "learn from doing" educational purposes. High comprehensive quality, reasonable knowledge structure and good normal students teaching skills and relevant research ability, students trained by such model can match the primary teachers' requirements of the main city and developed areas, and becoming the backbone of primary education in the future. 
The primary teacher training in the bachelor-master model is pay more attention to quality rather than quantity, and to win through high quality is its most obvious feature. Since the primary education lack of deserved social attention in a long-term, resulting the college entrance examination cannot absorb high-quality students, such model using bachelor-master "4+2"method to attract outstanding students to apply and in six years get a bachelor's degree and a master's degree. This mode is inadvisable to recruit too many people but should designedly cooperate with well-conditioned municipal primary schools like the Bashu primary school, Renmin primary school and Renhe Street primary school through the "order" training mode. In the first and second year in college, they are send to the country's leading integrated 985 colleges like Peking University, Wuhan University, Nanjing University, Zhejiang University to learn the humanities and natural sciences and other comprehensive knowledge, the third and fourth year return back to the normal college to study the normal professional conduct, teacher skills and art and physical skills, the fifth year go to the well-known primary school to start the teaching practice training and observe teaching training and the sixth year is the stage to training the ability of school based curriculum development and thesis writing. Students trained by this mode have high comprehensive quality, broad knowledge, and solid pedagogical skills and has formed relevant academic vision and certain research ability, and capable for higher education mission once graduated, they are the "leader sheep" in primary education, and school-based specialist in primary education and enable the primary education become more innovation and vitality in the future.

Imply the model of post-employment one year education program. For the existing primary education teachers, they can using one year program training mode to complete the transition toward general teachers. The major conditions of existing primary education teachers is a long vocation time, lagging behind teaching philosophy, abundant teaching experience and slowly update knowledge. To counter the actual teaching situation in Chongqing, the author proposed the training mode of post-employment one year education program for primary teachers who have a long-term teaching experience and enter relevant normal college to receive one year "melted down" training or one year university switching training mode.

Post-employment rotation training mode $(6+1)$ : the long time teaching work make people burnout easily, and forming a professional mindset which is bad for the healthy growth of teachers, thus the author proposed the post-employment rotation training mode $(6+1)$ to solve relevant issues. According to the characteristics of primary education, the post-employment rotation training mode defined six year as a teaching cycle, that is to say, selecting the teachers who finished one teaching cycle and one year off-job training and send to relevant universities to self-examination their teaching works and update their knowledge, within this year, they should complete relevant knowledge updating and thesis writing. In the process of off-job training, the thinking of teachers will be activated, and the working burnout will turned into potential energy, making in-service teachers realize vocation innovation, making some differences.

Interscholastic teacher one year exchange mode: the teacher exchange programs between regions and schools, it means between the schools in Chongqing city, the main city and inter-district, inter-district interscholastic exchanges to achieve the cross-regional, interscholastic exchanges, revitalizing the primary teaching resources of Chongqing and balance the regional advantages between primary schools, and radiating the education resources of developed area to the underdeveloped areas to promoting the fair of primary education. Based on the characteristics of primary education, this plan can applied three-year a period teacher exchange measures. The teacher exchange is not only the exchange of learning among teachers, but the teaching equipment in developed areas may also borrowed or sold at a discount way to these schools in underdeveloped 
areas, achieving the sharing and interoperability of teaching resources.

\section{Analysis of the curriculum design module of general teachers}

In the theory of teacher education, the teacher knowledge classification theory of Schulman is the most typical and effective one. He believes that teachers' knowledge is divided into seven parts: content (subject) knowledge, general teaching knowledge(principles of classroom management and organization), curriculum knowledge (teaching materials and lesson plans), general teaching methods and teaching knowledge, knowledge about learners, the knowledge about educational environment (team, community, culture, etc.) and the knowledge of educational value. The teacher knowledge classification of Schulman, objectively speaking, is quite comprehensive, to a certain extent offset the deficiency of ignoring student's practical ability in current education.

According to the teacher knowledge classification theory of Schulman, the curriculum module of general teacher training can be divided into following four parts. General education module, the corresponding public courses, as well as the basic of philosophical and historical knowledge; subject education module, that is the professional knowledge as a teacher like teaching about the relevant class management and education management knowledge; professional education module, namely the education professional knowledge skills as a general teachers which is more specific and professional compared with subject education module; activity practice modules, refers to the education environment knowledge, which focus on training of students' ability of society interact and activity organization abilities. The basic relationship between the four modules, its core is the professional education and subject education module, general education modules and activity practice modules as two wings, coordination, and join forces to promote the full development of primary general teachers training curriculum.

But it should be clear that general education module is the basis of training primary general teachers, subject education module is a prerequisite, professional education module is the safeguard, activity education module is the sustentation, and the four modules collectively construct the system structure for general teacher training curriculum.

General education module. General education module mainly related to the basic quality and ability requirements of our community to college students. The related courses except some basic skills but also should setting relevant humanities course and socio-economic affairs and generally improve the basic quality of students and understanding the development of our current society in a higher perspective. The setting of general education module will break the limitation of the inherit tradition that previous school year set under the existing training model and extend to the study of pre-three years, which facilitate student to better display the basic functions of general education module in learning of other modules. The class hour setting ratio of this module can be adjusted according to the actual needs of teaching, but is an indispensable part.

Subject education module. The subject education module part is both designed for teaching profession and bears the task of interconnect humanities and natural knowledge, enrich students' knowledge, and construct a comprehensive knowledge structure. This module is mainly concentrated in the middle four semesters, on the basis of learning some basic knowledge of the public to continue learning the content in different disciplines. The further integration of content from different disciplines systematized, so that both can be subdivided further and in a certain extent to combine all the knowledge together, and the success of constructing this module is related to the issue that whether the knowledge general teacher is "broad" or not. Thus, this module should has a higher proportion.

Professional education module. This module is more professional on the basis of subject 
education module and enters into the learning of more specialized knowledge and skills after grasp the relevant subject knowledge. The construction of this module is based on the setting of related subject courses in subject education module to increase the depth of courses setting and mainly solving the problem of whether the knowledge of general teachers is "profound" or not, and concentrated in the behind three semesters. The content of this module is hard to understand, but it decides the "value" of general teacher's knowledge, so it is the biggest part of these four modules.

Activity practice module. This module should run through the entire training cycle in various forms. In the first half part of the teaching cycle, it should concentrated inside school in the form of school activities, which mainly training students' communication ability, collaboration and organization abilities. With the deepening of education, activity education module can be extend to off-campus. As general teachers, they should bear the comprehensive teaching tasks and the design in activity education module is more complex and needs more methods. Here we can adjust the previous practice unidirectional mode into theory-practice-theory-practice such spiral rose pattern, thus the theory and practice will be more closely connected, and continuous improve training abilities and learning theories to fully enrich themselves.

In conclude, the reform and construct of primary teacher training mode is a complex, long term and progressive social system project, which related the community, schools and people's ideas and many other fields. On the basis of reflection of the current primary teacher training mode in Chongqing learning from the advanced training modules in both domestic and abroad following the general rules of primary education and the development of professional teacher education, try to build a new primary teacher training mode more scientific and diversified with more opening and flexibility and meet the requirements of Chongqing primary education development with the geographical features of Chongqing municipality.

\section{Acknowledgement}

This study is the results of "Study on the Course Design in General Primary School” CQGJ13B535, an important research project of Chongqing Institute of Higher Education.

\section{References}

[1] Chongqing Municipal Education Commission. Report on 2008 Chongqing education development in 2008, Chongqing Press: 2008 (1). (In Chinese)

[2] Jiang, Y. Subjective construction of primary teacher training model in bachelor level. Jiangsu Higher Education, 2008 (1). (In Chinese)

[3] Kang, H. considerations on primary education professional model. Journal of Jimei University, 2003 (4). (In Chinese)

[4] Zhou, J. consideration and exploration of the training model of primary professional teachers. Journal of Xinzhou Teachers University, 2007 (8). (In Chinese)

[5] Academic Administration of Beijing Normal University. Innovative model of teacher education, construct teacher education system of Chinese characteristics. Teacher Education Research, 2005 (3). (In Chinese) 